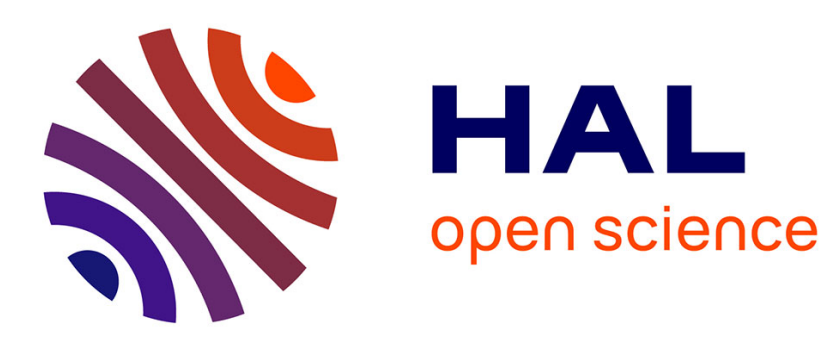

\title{
Study of organic contamination induced by outgassing materials. Application to the Laser MégaJoule optics
}

\author{
Jérôme Neauport, O. Favrat, B. Mangote, I. Tovena-Pécault
}

\section{To cite this version:}

Jérôme Neauport, O. Favrat, B. Mangote, I. Tovena-Pécault. Study of organic contamination induced by outgassing materials. Application to the Laser MégaJoule optics. Applied Surface Science, 2014, 293, pp.132-137. 10.1016/j.apsusc.2013.12.116 . cea-01692810

\section{HAL Id: cea-01692810 https://hal-cea.archives-ouvertes.fr/cea-01692810}

Submitted on 25 Jan 2018

HAL is a multi-disciplinary open access archive for the deposit and dissemination of scientific research documents, whether they are published or not. The documents may come from teaching and research institutions in France or abroad, or from public or private research centers.
L'archive ouverte pluridisciplinaire HAL, est destinée au dépôt et à la diffusion de documents scientifiques de niveau recherche, publiés ou non, émanant des établissements d'enseignement et de recherche français ou étrangers, des laboratoires publics ou privés. 


\title{
Study of organic contamination induced by outgassing materials. Application to the Laser Mégajoule optics
}

\author{
O. Favrat*, B. Mangote, I. Tovena-Pécault, J. Néauport \\ CEA Cesta, BP 2, 33114 Le Barp, France
}

\section{A R T I C L E I N F O}

\section{Article history:}

Received 13 September 2013

Received in revised form

19 December 2013

Accepted 20 December 2013

Available online 29 December 2013

\section{Keywords:}

Organic contamination

Outgassing

Thermodesorption

Sol-gel coating

VOCs

SVOCs

\begin{abstract}
A B S T R A C T
Organic contamination may decrease the targeted performances of coated surfaces. To study the contamination induced by surrounding materials, a method using a thermal extractor is presented in the first part of this work. Besides its normal operation (analyses of outgassing compounds from a material), this device is used in an original way to contaminate and decontaminate samples. Efficiency of contamination and decontamination protocols are assessed by automated thermal desorption and gas chromatography coupled with mass spectrometry and by secondary ion mass spectrometry coupled with a time of flight mass analyzer. This enables to study the contamination induced by a bulk material outgassing and to take in consideration the possible competition between outgassed species. This method is then applied to investigate contamination of Laser Mégajoule sol-gel coated optics by a retractable sheath. The impact of the temperature on the outgassing of the sheath has been highlighted. Increasing temperature from 30 to $50^{\circ} \mathrm{C}$ enables the outgassing of organophosphorous compounds and increases the outgassing of oxygenated compounds and phthalates. Chemical analyses of contaminated optics have highlighted affinities between the sol-gel coating and phthalates and organophosphorous, and low affinities with aromatics and terpens. Finally, samples with increasing levels of contamination have been realized. However a saturation phenomenon is observed at $90 \mathrm{ng} \mathrm{cm}^{-2}$.
\end{abstract}

(c) 2014 Elsevier B.V. All rights reserved.

\section{Introduction}

Surface coatings allow the optimization of the performances of a solid surface to a specific application. However, particle or molecular contamination can affect the targeted performances. Contamination generally comes from manufacturing processes (residues of solvents, detergents, or polishing products...), from human activities, from environment (molecules outgassed from packaging [1], or from surrounding materials [2]). Therefore, from the outset until nowadays, several activity fields - spatial [3-5], microelectronic [6-9], coating technologies [10], laser applications [11-14] - look for reducing contamination sources and study their impact on the surface properties. For example, for laser applications, contamination may impact the transmittance, the reflectance, or the laser-induced damage threshold (LIDT) of optics [15], limiting the development of high power lasers $[16,17]$. Therefore, several studies deal with intentional contamination of functional surfaces. For example, to study the impact of toluene on the LIDT of coated optics for space applications, Ling et al. [18-21] or Riede et al. [22] have developed protocols to

\footnotetext{
* Corresponding author. Tel.: +33 557045967.

E-mail address: olivier.favrat@cea.fr (O. Favrat).
}

contaminate some optics which consists in introducing toluene in the vacuum cell containing their samples. Riede et al.'s further studies [23] have also investigated laser induced contamination in vacuum in presence of bulk materials (silicone, polyurethane and epoxy based materials). In this way, for atmospheric pressure studies, a new method using a thermal extractor (Micro-Chamber Thermal Extractor: M-CTE250, Markes International) is here presented. Although the M-CTE is designed to study the molecules outgassed from a material [24], this paper presents a particular use of this system as a tool to contaminate and decontaminate samples. It enables in particular to use a bulk material for the optics contamination instead of one class of molecules to take into account possible competition and combinations between molecules. The molecules outgassed from a material are identified and quantified by automated thermal desorption and gaseous chromatography coupled with mass spectrometry (ATD/GC/MS) analyses that also enable to determine the affinity of outgassed molecules with a coated surface. In the first section of this paper, the M-CTE250 system and how it can be used to study contamination is described. Then, to illustrate this method, an application to the Laser MégaJoule optics (LMJ, a French multi beam facility) is performed: contamination of sol-gel coated silicate optics by outgassing of a retractable sheath is investigated in a second part. 


\section{Experimental}

\subsection{Experimental setup}

The intentional contamination test is realized in a qualified Micro-chamber/Thermal Extractor (M-CTE250 Markes International). The M-CTE250 is a quality control tool for screening the volatile and semi-volatile organic compounds (VOCs and SVOCs) coming out of organic materials. The system consists in four micro-chambers operating between ambient temperature and a maximum of $250^{\circ} \mathrm{C}$. Conditioned sorbent tubes are attached to each micro-chamber and a controlled flow of dry clean air passes throughout all four chambers simultaneously (Fig. 1). Organic compounds, which are not adsorbed on receptive surfaces, are swept from the chamber and collected onto attached sorbent tubes. Depending on the aim of the experiment, chambers are kept empty (to perform a blank procedure, Fig. 1a) or are filled with a contaminant alone (normal use, to determine the VOCs and SVOC outgassed from a material [24], Fig. 1b) or with a sample and a contaminant (to contaminate the sample, Fig. 1c) or with a sample alone (to desorb or to decontaminate it, Fig. 1d). This new use of the M-CTE has already been discussed in authors' previous work [25,26]. In the four cases, the outgassed molecules are trapped in the sorbent tubes which can be analyzed later.

\subsection{Extraction and collection of contaminant molecules}

Before any use of the M-CTE, it is cleaned to remove any residual contamination. The chambers of the M-CTE, the o-rings and the sample holders are first rinsed with ethanol (more than 99.9\% pure from VWR Prolabo) and cyclohexane (analytical reagent grade more than $99.95 \%$ pure from Fisher Chemical) and then are heated for $4 \mathrm{~h}$ at $250^{\circ} \mathrm{C}$ with a flow rate of $100 \mathrm{~mL} \mathrm{~min}^{-1}$ (configuration a. in Fig. 1).

For the contamination configuration, the desired quantity of contaminant is placed in the chambers. The sample is placed on the sample holder that avoids direct contact between the sample and the contaminant (configuration c. in Fig. 1). The chambers are heated at the desired temperature ( 30 or $50^{\circ} \mathrm{C}$ in this study) with a controlled flow rate. The air flow enables to homogenize the atmosphere in the chambers and to simulate the air exchange that occurs in cleanrooms. Once the required test duration is elapsed, the M-CTE is cooled for $30 \mathrm{~min}$ to reach ambient temperature and the samples are conditioned in low-outgassing boxes in PET-G (polyethylene terephthalate glycol). The contaminant can also be placed alone (without the sample) in the M-CTE for the outgassing material study (configuration b. in Fig. 1). At each step, the air flow circulates though the sorbent tubes and outgassed molecules are trapped.

The M-CTE is also used to analyze the contaminated samples. They are placed on the chambers (one per chamber) and are heated at 150,200 , and $250^{\circ} \mathrm{C}$ with a flow rate of $100 \mathrm{~mL} \mathrm{~min}^{-1}$ during two hours per temperature to extract volatile and semi-volatile compounds from the sample (configuration d. in Fig. 1). These molecules are trapped in the absorbent tubes.

\subsection{Absorbent tubes analysis}

Sorbent tubes used for these experiments are $250 \mathrm{mg}$ Tenax TA (60-80 mesh). Once the molecules are trapped, sorbent tubes are thermally desorbed and analyzed by gas-phase chromatography (GC) coupled with mass spectrometry (MS) Turbomass-Clarus 500 , PerkinElmer. The ATD/GC/MS analysis method is based on the ISO 16000-6 recommendations but has been modified to improve the detection of semi-volatile organic compounds, especially the phthalates. The exact parameters cannot be disclosed here. The quantification is calibrated by external calibration method using a reference compound, namely hexadecane $\left(\mathrm{C}_{16} \mathrm{H}_{34}\right.$, CAS registry number: 544-76-3), which means that the masses and concentrations of the outgassed compounds are expressed in hexadecane equivalents.

\subsection{Application on Laser MégaJoule optics}

To provide an example of this contamination-decontamination protocol, contamination of sol-gel coated optics of the Laser MégaJoule, a French multi laser beam facility by a retractable sheath is now studied.

\subsubsection{Sol-gel coated optics}

$7000 \mathrm{~m}^{2}$ of the 10,000 large-sized optical components of the LMJ are coated with a sol-gel antireflective layer [26]. However, due to its high porosity ( $\sim 57 \%$ ) [27], the coating may be very sensitive to molecular contamination. Therefore, such sol-gel coated surfaces are chosen to assess the contamination and decontamination protocols. $50 \mathrm{~mm}$-diameter, $5 \mathrm{~mm}$-thick, plano-parallel Corning 7980 fused silica polished samples are used. Substrates are double side polishing and finished with fine polishing. A single antireflective coating made of nanosized spherical particles of amorphous silica is deposited by dip-coating in a colloidal suspension. After deposition and solvent evaporation, the nanoparticles of silica do not pack perfectly together and give rise to a porous film. Deposited onto both sides of the substrate, this antireflective coating allows to reach practically a transmission value of $100 \%$ at a single wavelength of $351 \mathrm{~nm}$. The absence of chemical bond between independent silica particles and with the substrate caused for coating to be very sensitive to scratch. To improve the coating scratch resistance, a treatment with ammonia vapors is realized. A particle-to-particle surface base-catalyzed condensation generates shrinkage of the coating thickness, but the porosity and hence, the refractive index remains unchanged [28].

\subsubsection{Contaminant}

The contaminant selected for this study is a polyurethane coated polyester retractable sheath used on the LMJ facility as a ventilation shaft (Aero Textile Concept). This material is chosen because huge amount of this sheath is used close to the optics in LMJ. Moreover, as many polymers with additives, it may outgass some organic compounds that could be adsorbed on the sol-gel coated surfaces.

\section{Results and discussion}

\subsection{Highlight of initial contamination}

Analysis by ATD/GC/MS of a dry extract has highlighted a contamination of the colloidal silica bath mainly by phthalates and oxygenated compounds. Indeed the sol-gel solution used for the antireflective treatment has been used for several years and may contain some contaminants. This contamination may come from the outgassing or migration of species from the polypropylene container of the colloidal silica solution and is transferred to the samples during the treatment. Thus, to remove this contamination, a cleaning by thermodesorption is done. The cleaning protocol is close to the thermodesorption protocol used for the samples analyses. It consists in heating the optics at 150,200 , and $250^{\circ} \mathrm{C}$ during an hour per temperature, with a flow rate of $100 \mathrm{~mL} \mathrm{~min}^{-1}$. The outgassing products gathered during the thermodesorption of two different antireflective treated optics are exposed in Table 1.

After this cleaning procedure, ATD/GC/MS analyses are done to check the efficiency of the cleaning. Only $2 \mathrm{ng} \mathrm{cm}^{-2}$ for sample 1 and $8 \mathrm{ng} \mathrm{cm}^{-2}$ for sample 2 of phthalates are detected. 

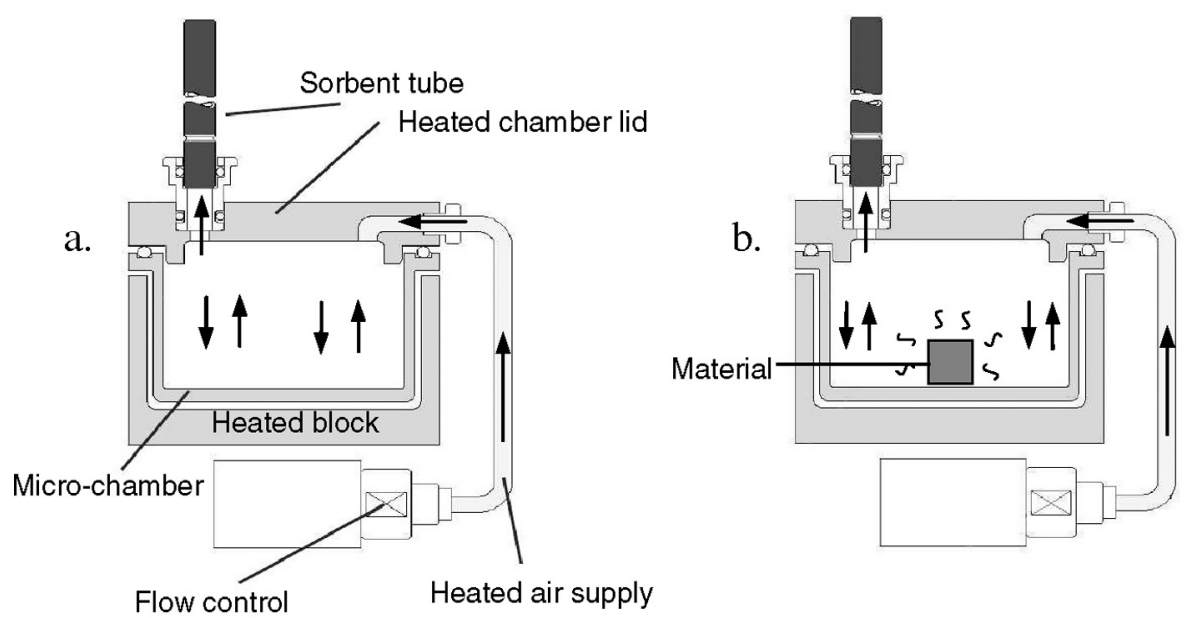

Flow control

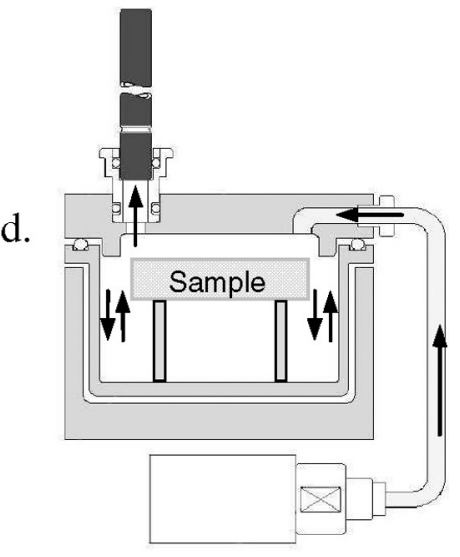

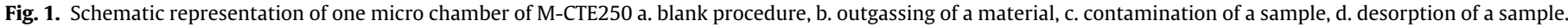

Table 1

Molecules gathered during the cleaning process.

\begin{tabular}{|lll|}
\hline & $\begin{array}{l}\text { Sample 1 } \\
\text { concentration } \\
\left(\mathrm{ng} \mathrm{cm}^{-2}\right)\end{array}$ & $\begin{array}{l}\text { Sample 2 } \\
\text { concentration } \\
\left(\mathrm{ng} \mathrm{cm}^{-2}\right)\end{array}$ \\
\hline Phthalates & 454 & 614 \\
\hline Oxygenated compounds & 13 & 12 \\
\hline Other compounds & 3 & 3 \\
\hline Sum of quantified compounds & 470 & 629 \\
\hline
\end{tabular}

To confirm the results obtained by ATD/GC/MS, i.e., the presence of initial contamination and the efficiency of the thermodesorption, analyses of initial and residual compound present on the optics are realized by secondary ion mass spectrometry coupled with a time of flight mass analyzer (ToF-SIMS).

Analyses of residual compounds present on the optics are also realized by secondary ion mass spectrometry coupled with a time of flight mass analyzer (ToF-SIMS). Primary ions $\left(\mathrm{Bi}_{3}{ }^{+}\right)$with energy of $25 \mathrm{keV}$ are produced by a pulsed source and sent on optical coating surface. The collision induces secondary ions which are focalized and accelerated inside the time of flight mass analyzer. The obtained mass spectra represent the intensity of secondary ions in function of their masses. Areas of $200 \times 200 \mu \mathrm{m}^{2}$ are used for the acquisition of each kind of ions (positive and negative ions). The static mode is chosen to inform on the extreme surface layer (about $1 \mathrm{~nm}$ ). Five areas of analysis by polarity were realized (five spectra for positive ions and for negative ions).

Intensities of the more significant peaks are summarized in Table 2. These values correspond to the average intensities, normalized by the total emission of secondary ions, obtained on the five analysis points (five spectra for positive ions and for negative ions). The standard deviation (SD) gives the dispersion of the analysis assessment inside each sample. Only the results on the same ion can be compared and represent a trend because ToF-SIMS is a semi quantitative method. Results are quite similar between the samples. The molecular analysis of positive ions reveals an initial contamination by phthalates, hydrocarbonated, and oxygenated compounds. The thermodesorption enables to decrease this contamination (from 32,000 to 11,000 for $\mathrm{C}_{x} \mathrm{H}_{y}{ }^{+}$and from 5300 to about 300 for the phthalates). However, oxygenated compounds were not detected by ATD/GC/MS, meaning that the cleaning process does not remove the whole contamination desorption but strongly decreases it. After the thermodesorption, as less contamination hides the surface, some values are enhanced $\left(\mathrm{Si}_{w} \mathrm{H}_{y} \mathrm{O}_{z}{ }^{-}, \mathrm{SO}_{x}{ }^{-}, \mathrm{Na}^{+}\right.$, $\mathrm{PO}_{x}{ }^{-}, \mathrm{F}^{-}$, and Tinuvin 328). The negative ions $\mathrm{Si}_{w} \mathrm{H}_{y} \mathrm{O}_{z}{ }^{-}$comes from the treated silica substrate itself. Analysis of an uncoated sample has also revealed the presence of $\mathrm{Na}^{+}, \mathrm{PO}_{x}^{-}, \mathrm{SO}_{x}{ }^{-}$, and $\mathrm{F}^{-}$, suggesting that these compounds are present on the bare silica sample (residues of polishing or cleaning processes, as it has already been observed $[29,30])$. These impurities might have been diffused in the sol-gel coating or might have gradually contaminated the sol-gel solution as the same bath is used for consecutive treatment for years. Otherwise, Tinuvin 328 is only found on coated samples and thus comes from the sol-deposition process (sol-gel solution or dipping though).

Although it is not the aim of the present study, it is essential to outline that the optical performances of the optics (transmittance and laser-induced damage threshold) have been tested before and after the cleaning procedure. These characteristics have not been modified [25,26]. 
Table 2

Results of ToF-SIMS analysis on sol-gel anti reflection coatings.

\begin{tabular}{|c|c|c|c|c|c|c|c|c|}
\hline & \multicolumn{4}{|c|}{ Before cleaning (arbitrary units) } & \multicolumn{4}{|c|}{ After cleaning (arbitrary units) } \\
\hline & \multicolumn{2}{|c|}{ Sample 1} & \multicolumn{2}{|c|}{ Sample 2} & \multicolumn{2}{|c|}{ Sample 1} & \multicolumn{2}{|c|}{ Sample 2} \\
\hline & Mean & SD & Mean & SD & Mean & SD & Mean & SD \\
\hline $\mathrm{C}_{x} \mathrm{H}_{y}^{+}$ & 31,947 & 434 & 31,929 & 829 & 10,691 & 245 & 11,250 & 359 \\
\hline Aromatic & 1215 & 12 & 1208 & 17 & 881 & 25 & 869 & 64 \\
\hline $\mathrm{C}_{x} \mathrm{H}_{y} \mathrm{O}^{+}$ & 1596 & 51 & 1634 & 88 & 2984 & 59 & 2537 & 175 \\
\hline Phthalate & 5359 & 377 & 5333 & 386 & 290 & 29 & 408 & 14 \\
\hline Tinuvin 328 & 17 & 2 & 10 & 2 & 150 & 12 & 80 & 7 \\
\hline $\mathrm{Na}^{+}$ & 51 & 6 & 56 & 3 & 143 & 12 & 183 & 108 \\
\hline $\mathrm{PO}_{x}^{-}$ & 204 & 7 & 197 & 12 & 1457 & 174 & 1488 & 282 \\
\hline $\mathrm{SO}_{x}^{-}$ & 17 & 5 & 16 & 2 & 65 & 7 & 152 & 191 \\
\hline $\mathrm{Si}_{w} \mathrm{H}_{y} \mathrm{O}_{z}^{-}$ & 7713 & 387 & 7539 & 404 & 10,628 & 558 & 10,096 & 803 \\
\hline $\mathrm{F}^{-}$ & 49 & 3 & 50 & 4 & 6214 & 895 & 6479 & 1342 \\
\hline
\end{tabular}

Consequently the thermodesorption can be considered as a good sol-gel coating decontamination technique. An important part of the contamination is removed and above all, a reference state of surface cleanliness is reached for all the optics before intentional contamination study by the sheath outgassing. Thus, this decontamination protocol is applied on each sol-gel coated optic prior to any analysis or intentional contamination.

\subsection{Outgassing of contaminant}

The contaminant selected for this study is a textile retractable sheathing used on the LMJ facility as a clean isolator. $2 \mathrm{~g}$ of this material have been placed during $48 \mathrm{~h}$ at two temperatures, 30 and $50{ }^{\circ} \mathrm{C}$ with a flow rate of $100 \mathrm{~mL} \mathrm{~min}^{-1}$ with and without a desorbed (according to the protocol explained Section 3.1) optical component i.e., the configurations c. and b. in Fig. 1. The temperatures have been chosen to enhance the desorption of the sheath while remaining close to the cleanroom temperature $\left(20^{\circ} \mathrm{C}\right)$ and to simulate local temperature rises $\left(50^{\circ} \mathrm{C}\right)$. Fig. 2 recapitulates the

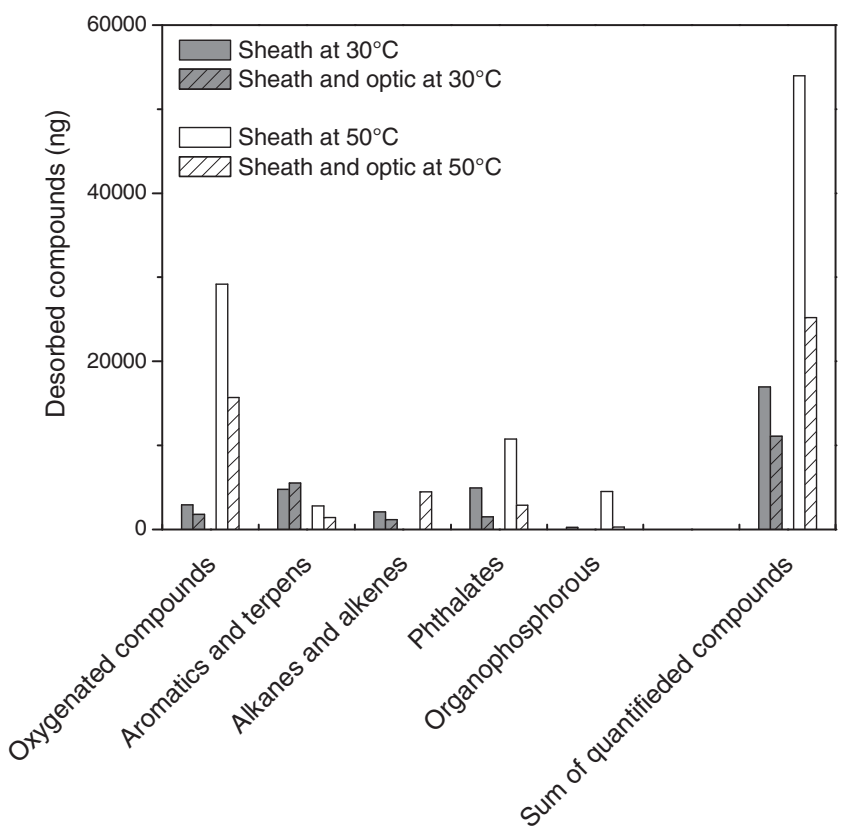

Fig. 2. Outgassed compounds from the textile sheath with and without an optical component. outgassed compounds for the different temperatures and configurations.

The analysis of the sheath alone shows that as expected, increasing temperature increases the desorption of the sheath. Desorption is three times more important at $50^{\circ} \mathrm{C}$ than at $30^{\circ} \mathrm{C}$. Although the outgassed compounds are same at 30 and at $50^{\circ} \mathrm{C}$, the ratio differs. At $50^{\circ} \mathrm{C}$, oxygenated compounds are mainly outgassed (nearly $30,000 \mathrm{ng} /$ tube), then phthalates (about 10,000 ng/tube) and organophosphorous compounds (5000 ng/tube). Otherwise, at $30{ }^{\circ} \mathrm{C}$, aromatics/terpens and phthalates are the most gathered compounds (almost $5000 \mathrm{ng} /$ tube). Only few organophosphorous compounds are found (about $200 \mathrm{ng} \mathrm{cm}^{-2}$ ).

Once an optical component is added, molecules are adsorbed on it, so fewer molecules are gathered in the sorbent tube. It provides information about the molecules adsorbed on the sample. By comparing the full and the hatch columns of Fig. 2, it can be expected that at $50^{\circ} \mathrm{C}$, the sample would be contaminated by oxygenated compounds, phthalates, and organophosphorous, whereas at $30^{\circ} \mathrm{C}$, the contamination would be essentially caused by the phthalates.

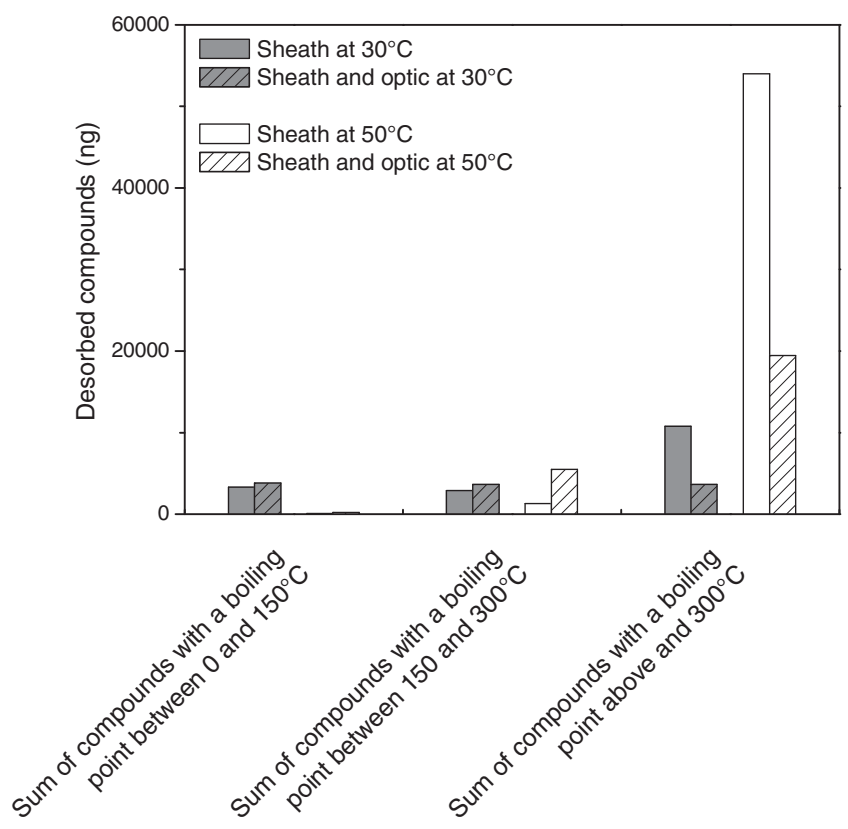

Fig. 3. Molecules outgassed from the textile sheath as a function of their boiling point. 

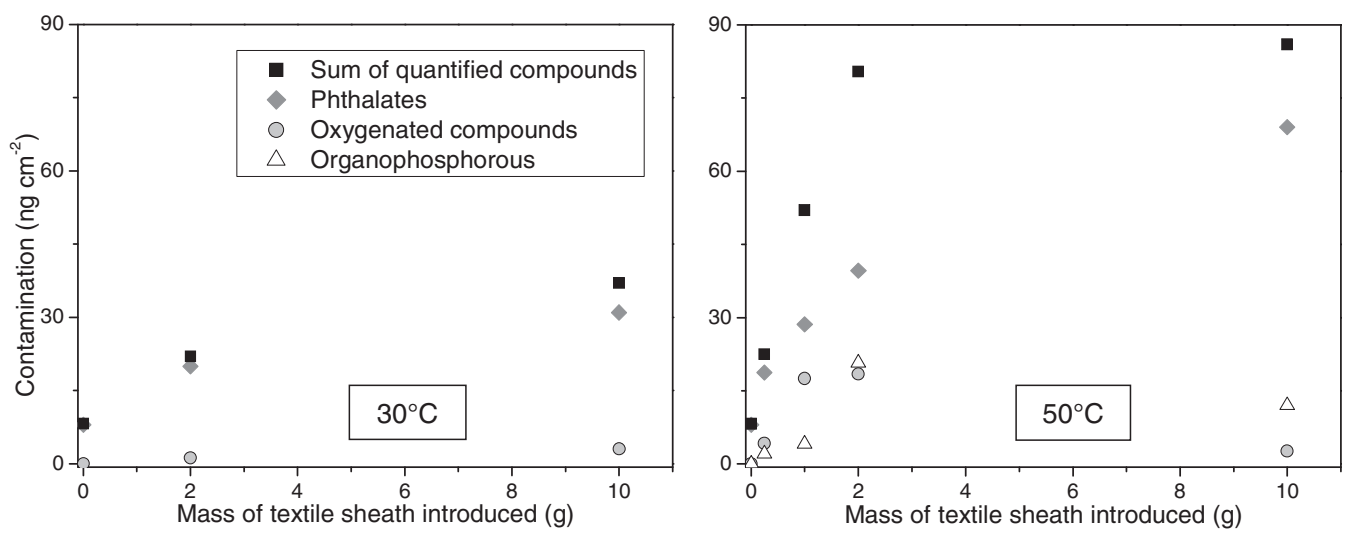

Fig. 4. Organic contamination as a function of the mass of textile sheath

As Tenax TA tubes have low breakthrough values for organic compounds with a low boiling point and a low vapor pressure [31], it was checked that breakthrough volumes have not been reached after $48 \mathrm{~h}$. For this purpose, two Tenax TA tubes were linked together tanks to a perfluoroalkoxy join. The tubes were used for an outgassing experiment for $48 \mathrm{~h}$ at $50^{\circ} \mathrm{C}$ with $2 \mathrm{~g}$ of textile sheath in the chamber and a flow rate of $150 \mathrm{~mL} \mathrm{~min}^{-1}\left(>100 \mathrm{~mL} \mathrm{~min}^{-1}\right.$ to compensate the air resistance due to the second tube). Analysis of both tubes revealed that no organic compounds were trapped in the second tube, meaning that breakthrough phenomenon did not occur.

Molecules outgassed from the sheath can also be classified as a function of their boiling point to differentiate VOCs and SVOCs (Fig. 3).

Whatever the temperature is ( 30 and $50^{\circ} \mathrm{C}$ ), outgassed compounds are mainly compounds with a high boiling point (above $300^{\circ} \mathrm{C}$ ). When a sample is added in the micro-chamber, desorption of high boiling point molecules significantly decreases whereas few variations are observed for medium and low ebullition point molecules, meaning that the sol-gel coating is more sensitive to the SVOCs than to the VOCs.

This first part shows how the desorption is enhanced by the temperature. In particular, important desorptions of oxygenated compounds and organophosphorous are observed at $50^{\circ} \mathrm{C}$. Thus, although cleanrooms are regulated at $20^{\circ} \mathrm{C}$, local rises of temperature have to be avoided. Thanks to Figs. 2 and 3, a first idea of the molecules adsorbed on the sample has been established. Then, the chemical analyses by thermodesorption of the optics enable to know accurately the nature and quantity of contamination on the surface of the optics and to confirm the trends.

\subsection{Contamination of the optical components}

Optics alone are analyzed in this part (configuration d. in Fig. 1) by ATD/GC/MS to determine nature and quantity of the contamination adsorbed. To investigate the influence of the quantity of contaminant, different masses of sheath have been introduced in the chambers of the M-CTE to pollute the samples (configuration c. in Fig. 1). The results are presented in Fig. 4.

As expected, the contamination increases when more textile sheath is added. However, at $50^{\circ} \mathrm{C}$, the contamination of the sample is close for 2 and $10 \mathrm{~g}$ of textile sheath $\left(80.4\right.$ versus $\left.86 \mathrm{ng} \mathrm{cm}^{-2}\right)$. Moreover, a contamination process during $168 \mathrm{~h}$ instead $48 \mathrm{~h}$ has shown that increasing time of contamination does not enable to increase the contamination adsorbed on the optic component. Therefore, a saturation of the optic surface is here observed.

As it was suggested in Section 3.3, at $30^{\circ} \mathrm{C}$, contamination is made up of more than $80 \%$ of phthalates whereas at $50^{\circ} \mathrm{C}$, the contamination is more heterogeneous. One can see that although the sum of quantified compounds is similar at $50^{\circ} \mathrm{C}$ between 2 and $10 \mathrm{~g}$ of textile sheath introduced, the ratio differs. Adsorption of phthalates on the surface of the component still increases whereas less oxygenated compounds and organosphosphorous are found, underlining the affinities between the sol-gel coating and the phthalates. It can also be noticed that the aromatic and terpens are outgassed from the sheath (Fig. 2) but only traces $\left(<1 \mathrm{ng} \mathrm{cm}^{-2}\right)$ are found on the samples.

It also appears that molecules adsorbed on the surface of the samples are mainly molecules with a high boiling point, as it could be predicted by Fig. 3: whatever the temperature of the contamination process and the mass of textile sheath introduced are, molecules with a boiling point up to $300^{\circ} \mathrm{C}$ represent more than $90 \%$ of the detected contamination.

\section{Conclusion}

A method to study the organic contamination induced by a bulk outgassing material is here introduced. A thermal extractor has been diverted from its conventional use to contaminate and to decontaminate surfaces. Chemical analyses are then performed by automated thermal desorption and gaseous chromatography coupled with mass spectrometry to know the nature and the quantities of organic compounds. To illustrate this method, the study of the contamination of Laser MégaJoule sol-gel coated optics by a retractable sheath has been exposed. The impact of the temperature on the outgassing material and the affinities between sol-gel coating and the organic compounds outgassed has been highlighted. Finally, by introducing different masses of textile sheath, samples with different levels of organic contamination (between 20 and $90 \mathrm{ng} \mathrm{cm}^{-2}$ ) have been realized. At $50^{\circ} \mathrm{C}$, a saturation phenomenon does not enable to perform a contamination layer more than $90 \mathrm{ng} \mathrm{cm}^{-2}$. This method will then be applied to assess the influence of organic contamination on the performances (transmission and LIDT) of the Laser MégaJoule optics.

\section{Acknowledgements}

The authors would like to thank TERA Environnement (Fuveau, France) for ATD/GC/MS analyses and Biophy Research (Fuveau, France) for ToF-SIMS analyses.

\section{References}

[1] K. Bien-Aimé, C. Belin, L. Gallais, P. Grua, E. Fargin, J. Néauport, I. Tovena-Pécault, Impact of storage induced outgassing organic contamination on laser induced damage of silica optics at $351 \mathrm{~nm}$, Opt. Express 17 (2009) 18703-18713. 
[2] G. Guéhenneux, M. Veillerot, I. Tovena-Pécault, Evaluation of the airborne molecular contamination inside the LIL, Nucl. Instrum. Meth. A 557 (2006) 676-683.

[3] J.A. Muscari, P. Westcott, Optical contamination evidence from Skylab and Gemini flights, Appl. Opt. 14 (1975) 2883-2891.

[4] W.R. Hunter, Optical contamination: its prevention in the XUV spectrographs flown by the U.S. naval research laboratory in the Apollo telescope mount, Appl. Opt. 16 (1977) 909-916.

[5] E. Grossman, I. Gouzman, Space environment effects on polymers in low earth orbit, Nucl. Instrum. Meth. B 208 (2003) 48-57.

[6] B.M. Mertens, B. van der Zwan, P.W.H. de Jager, M. Leenders, H.G.C. Werij, J.H.P. Benschop, A.J.J. Disseldonk, Mitigation of surface contamination from resist outgassing in EUV lithography, Microelectron. Eng. 53 (2000) 659-662.

[7] D. Lu, R. Kumar, C.-K. Chang, A.-Y. Du, T.K.S. Wong, Analysis of surface contamination on organosilicate low k dielectric materials, Microelectron. Eng. 77 (2005) 63-70.

[8] D. Zhang, Y. Wang, Y. Gan, Characterization of critically cleaned sapphire single-crystal substrates by atomic force microscopy, XPS and contact angle measurements, Appl. Surf. Sci. 274 (2013) 405-417, 2013.

[9] A.E. Duisterwinkel, A.T.G.M. Bastein, W. van Schaik, Feasibility of UV cleaning of $157 \mathrm{~nm}$ reticles, Microelectron. Eng. 67-68 (2003) 3-9.

[10] C. Savall, A. Godon, J. Creus, X. Feaugas, Influence of deposition parameters on microstructure and contamination of electrodeposited nicke coatings from additive-free sulphamate bath, Surf. Coat. Tech. 206 (2012) 4394-4402.

[11] M.J. Soileau, W.E. Williams, E.W. Van Stryland, M.A. Woodall, Laser-induced damage measurements in CdTe and other II-VI materials, Appl. Opt. 21 (1982) 4059-4062.

[12] F.Y. Génin, M.D. Feit, M.R. Kozlowski, A.M. Rubenchick, A. Salleo, J. Yoshiyama, Rear-surface laser damage on $355 \mathrm{~nm}$ silica optics owing to Fresnel diffraction on front-surface contamination particles, Appl. Opt. 39 (2000) 3654-3663.

[13] X. Li, J. Shen, The stability of sol-gel silica coatings in vacuum with organic contaminants, J. Sol-Gel Sci. Technol. 59 (2011) 539-545.

[14] X. Wang, J. Shen, A review of contamination-resistant antireflective sol-gel coatings, J. Sol-Gel Sci. Technol. 61 (2011) 206-212.

[15] Y. Cui, Y. Zhao, H. Yu, H. He, J. Shao, Impact of organic contamination on laserinduced damage threshold of high reflectance coatings in vacuum, Appl. Surf Sci. 254 (2008) 5990-5993.

[16] D. Ristau, M. Jupé, K. Starke, Laser damage thresholds of optical coatings, Thin Solid Films 518 (2009) 1607-1613.

[17] X. Ling, Y. Zhao, D. Li, J. Shao, Z. Fan, Damage investigations of AR coating under atmospheric and vacuum conditions, Opt. Laser Technol. 41 (2009) 857-861.
[18] X. Ling, Y. Zhao, D. Li, S. Li, M. Zhou, J. Shao, Z. Fan, Impact of organic contamination on the laser-induced damage in vacuum, Appl. Surf. Sci. 255 (2009) 9255-9258.

[19] X. Ling, Y. Zhao, J. Shao, Z. Fan, Effect of two organic contamination modes on laser-induced damage of high reflective films in vacuum, Thin Solid Films 519 (2010) 296-300.

[20] X. Ling, G. Wang, Y. Zhao, X. Liu, J. Shao, Laser-induced damage of the optical coatings due to organic contamination in vacuum, Appl. Surf. Sci. 270 (2013) 346-351, 2013.

[21] X. Ling, Y. Zhao, X. Liu, M. Zhou, J. Shao, Z. Fan, Comparative study of laser-induced damage of two reflective coatings in vacuum due to organic contamination, Optik 123 (2012) 1453-1456.

[22] W. Riede, P. Allenspacher, H. Schröder, D. Wernham, Y. Lien, Laser-induced hydrocarbon contamination in vacuum, Proc. SPIE 5991 (2005).

[23] W. Riede, H. Schröder, G. Bataviciute, D. Wernham, A. Tighe, F. Pettazzi, J. Alves, Laser-induced contamination on space optics, Proc. SPIE 8190 (2011).

[24] M. Keller, U. Gommel, A. Verl, Measurement and classification method regarding the emission of volatile organic compounds from cleanrooms materials, in: International Symposium on Contamination Control ICCCS 2012, 2012.

[25] B. Mangote, I. Tovena-Pécault, J. Néauport, Decontamination of optics before organic contamination study and impact on the optics performance, in: International Symposium on Contamination Control ICCCS 2012, 2012.

[26] I. Tovena-Pécault, B. Mangote, Analyse de la contamination chimique d'optiques par chromatographie gazeuse couplée à la spectrométrie de masse, in: ASPEC, Contaminexpert 2013, 2013.

[27] P. Belleville, P. Prené, C. Bonnin, L. Beaurain, Y. Montouillout, E. Lavastre, How smooth chemistry allows high power laser optical coating preparation, Proc. SPIE 5250 (2011) 196-202.

[28] P. Belleville, Functional coatings: the sol-gel approach, C. R. Chimie 13 (2010) 97-105.

[29] J. Néauport, L. Lamaignère, H. Bercegol, F. Pilon, Birolleau, Polishing-induced contamination of fused silica optics and laser induced damage density at $351 \mathrm{~nm}$, Opt. Express 13 (2005) 10163-10171.

[30] J. Néauport, P. Cormont, L. Lamaignère, C. Ambard, F. Pilon, H. Bercegol, Concerning the impact of polishing induced contamination of fused silica optics on the laser-induced damage density at $351 \mathrm{~nm}$, Opt. Commun. 281 (2008) 3802-3805.

[31] E. Gallego, F.J. Roca, J.F. Perales, X. Guardino, Comparative study of the adsorption performance of a multi-sorbent bed (Carbotrap, Carbopack X, Carboxen 569) and a Tenax TA adsorbent tube for the analysis of volatile organic compounds (VOCs), Talanta 81 (2010) 916-924. 